\title{
Human Body via Art
}

\author{
Tamir A* \\ Chemical Engineering Department, Emeritus Professor of Ben-Gurion University of the Negev
}

${ }^{*}$ Corresponding author: Abraham Tamir, Chemical Engineering Department, Emeritus Professor of Ben-Gurion University of the Negev (Israel) Braham Tamirat, Tel: 913241339, E-mail: abrishntamirat@gmail.com

Citation: Tamir A (2017) Human body via art. J Forensic Crime Stu 1: 102

Article history: Received: 7 January 2017, Accepted: 31 March 2017, Published: 03 April 2017

The human body is the entire structure of a human being and comprises a head, neck, trunk (which includes the thorax and abdomen), arms and hands, legs and feet. Every part of the body is composed of various types of cell. At maturity, the estimated average number of the cells in the body is given as 37.2 trillion. The number given is arrived at by totaling the cell numbers of the organs of the body and cell types. The composition of the human body shows to be composed of a number of certain elements such as $\mathrm{Ca}_{2}, \mathrm{Na}+\mathrm{K}+, \mathrm{C}$, etc, in different proportions. The study of Human body involves anatomy and physiology. The human body can show anatomical non-pathological anomalies, which need to be able to be recognized. Physiology focuses on the systems and their organs of the human body and their functions. Many systems and mechanisms interact in order to maintain homeostasis skull, temple, ear, forehead, face, shoulder, nipple, breast, armpit, thorax, navel, abdomen, pubis, groin, knee, foot, toe, and ankle. Figure 1 painted by the American artist Alex Grey (b.1953) demonstrates human brain that is an organ that serves as the center of the nervous system. It is located in the head and is the most complex organ in the body. It is estimated to contain 15-33 billion neurons that communicate with one another by means of long protoplasmic fibers called axons. The brain is considered as a biological computer that acquires information from the surrounding world, stores it, and processes it in variety of ways, analogous to the central processes unit in a computer. Figure 2 demonstrate fingers that are organs of manipulation and sensation. Human fingers contain no muscles and are controlled by muscles in the arm and palm pulling on tendons. Figure 3 demonstrates human eyes painted by the Israeli artist Rami Meiri. The human eye is the organ that reacts to light and has several purposes where the major one is that it allows vision and can distinguish about 10 million colors. Figure 4 demonstrates the ear painted by Salvador Dali (1904-1989) a Spanish surrealist painter. The ear is the organ that detects sound, but also aids in balance and body position. Figure 5 demonstrates human leg fingers painted by Rene Magritte (1898-1967) a Belgian surrealist artist. Their names are big toe, second toe, middle toe, fourth toe and pinky toe. Legs are used for standing, walking, jumping running and similar activities. Figure 6 is a surrealist painting by an unknown artist of the inside of the human abdomen demonstrating the two lungs, the pancreas and the intestines. Figure 7 by Alex Grey demonstrates the human skeleton that is the internal framework of the body. It is composed of 270 bones. The skeleton serves six major functions: support, movement, protection, production of blood cells, storage of ions and endocrine regulation. And finally Figure 8 "David" by the Italian Michelangelo (1475-1564) demonstrates the complete human body. 

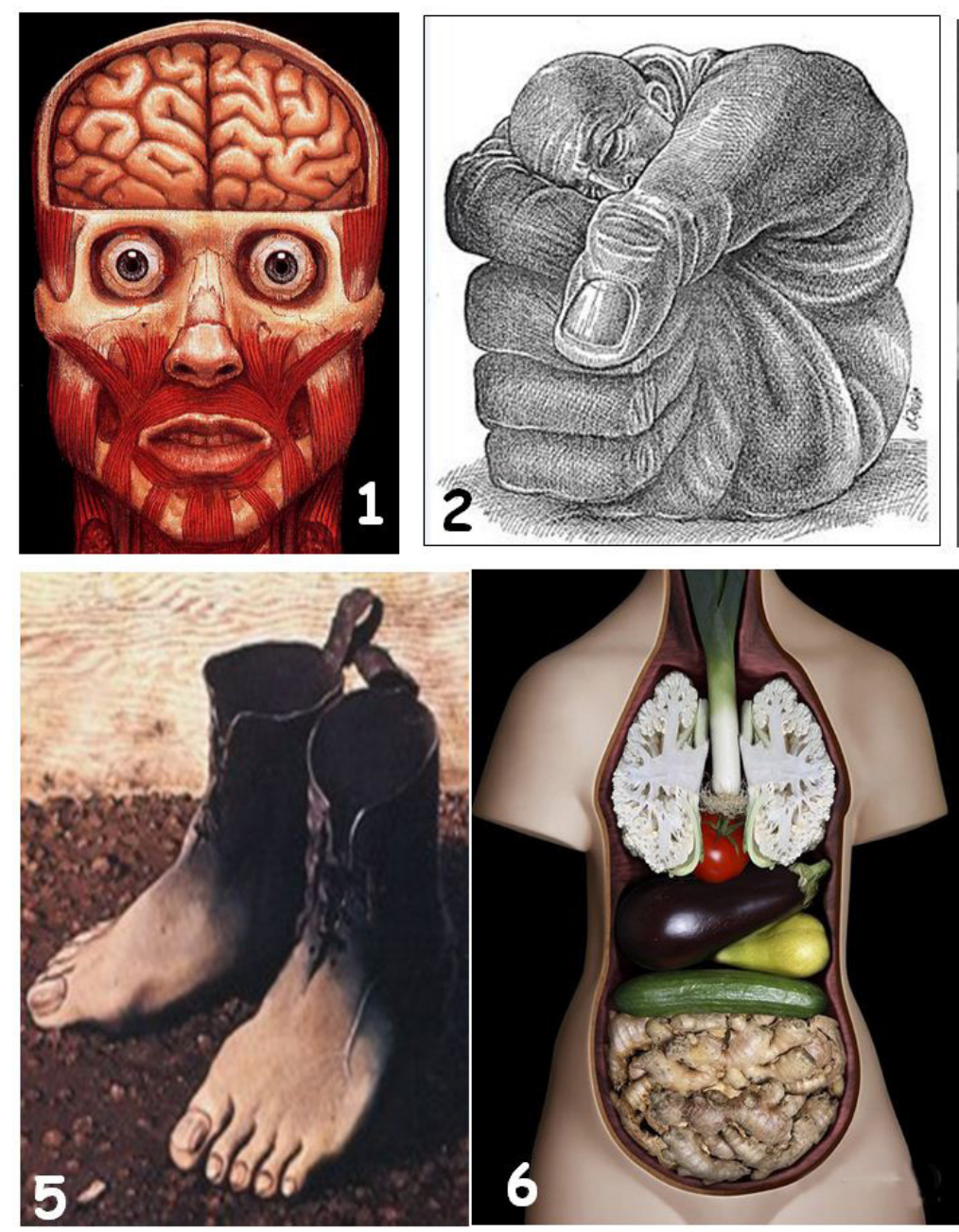
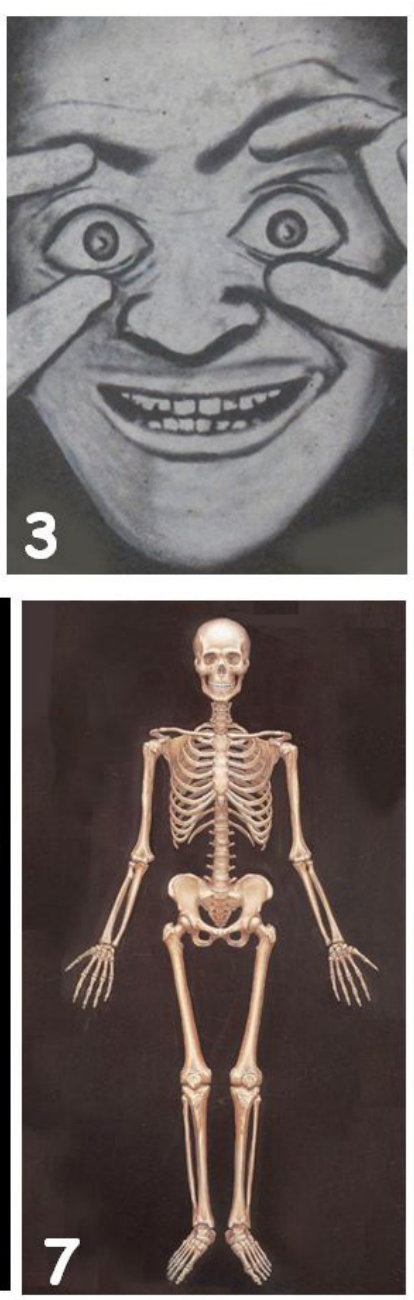
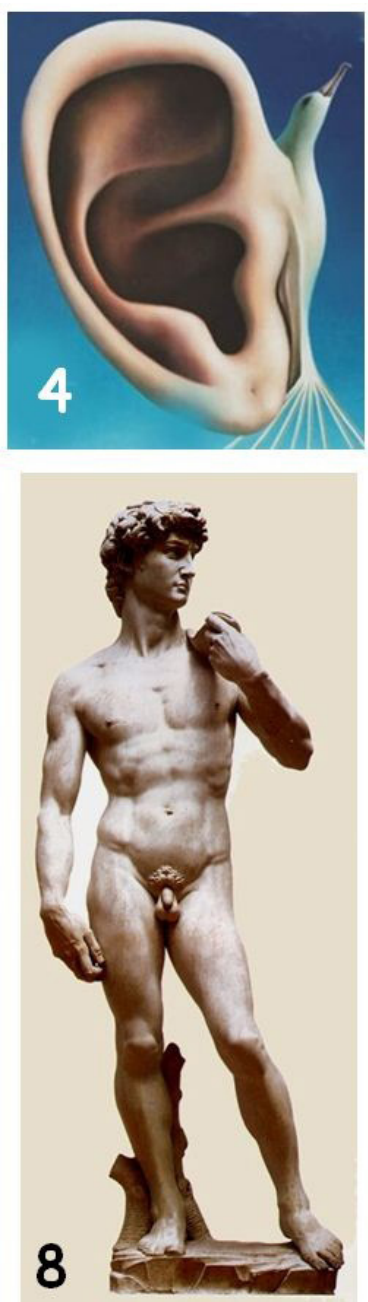